\title{
Cloning and sequencing show that 4- hydroxybenzoate hydroxylase (PobA) is required for uptake of 4-hydroxybenzoate in Rhizobium leguminosarum
}

\author{
Cheryl M. Wong, Michael J. Dilworth and Andrew R. Glenn \\ Author for correspondence: Andrew R. Glenn. Tel: +619360 6158. Fax: +6193103505. \\ e-mail: arglenn@ csuvax.csu.murdoch.edu.au
}

Nitrogen Fixation Research Group, School of Biological and Environmental Sciences, Murdoch University, Murdoch, Western Australia 6150, Australia

\begin{abstract}
Mutants of Rhizobium leguminosarum bv. viciae MNF300 and $R$. leguminosarum bv. trifolii WU95 unable to accumulate 4-hydroxybenzoate lack 4-hydroxybenzoate hydroxylase. The capacity of these mutants to take up and grow on 4-hydroxybenzoate was restored by a $2.0 \mathrm{~kb}$ EcoRI-Pstl DNA fragment. This contained only one ORF which had over $60 \%$ DNA sequence similarity with the structural gene for 4-hydroxybenzoate hydroxylase (pobA) from Pseudomonas spp. and Acinetobacter. Reported effects of metabolic inhibitors and substrate analogues on the apparent uptake of 4-hydroxybenzoate have now been shown to be due to their direct effect on 4-hydroxybenzoate hydroxylase. We propose that uptake of 4-hydroxybenzoate is via a metabolic 'drag' mechanism dependent on the activity of the pobA gene product.
\end{abstract}

Keywords: Rbizobium leguminosarum, aromatic substrate uptake, 4-hydroxybenzoate,
sequence of $p \circ b$,
Keywords: Rbizobium leguminosarum, aromatic substrate uptake, 4-hydroxybenzoate,
sequence of $p \circ b A$

\section{INTRODUCTION}

Many bacteria degrade aromatic substrates via the catechol and protocatechuate branches of the 3-oxoadipate pathway (Stanier \& Ornston, 1973). Rbizobium leguminosarum bv. trifolii (hereafter referred to as $R$. trifolii) TA1 possesses both pathways (Chen et al., 1984) whereas $R$. trifolii WU95 and R. leguminosarum bv. viciae (hereafter referred to as $R$. leguminosarum) MNF300 have only the protocatechuate branch (Chen et al., 1984). Growth of $R$. leguminosarum and $R$. trifolii on 4-hydroxybenzoate or protocatechuate requires enzyme induction; Chen et al. (1984) showed that 4-hydroxybenzoate hydroxylase and protocatechuate 3,4-dioxygenase were induced in the presence of 4-hydroxybenzoate. Growth on protocatechuate resulted in induction of protocatechuate dioxygenase, but not 4-hydroxybenzoate hydroxylase (Chen $e t$ al., 1984; Wong et al., 1991).

Despite detailed work on the catabolic enzymes involved in the 3-oxoadipate pathway, mostly in Pseudomonas (Stanier \& Ornston, 1973; Wheelis, 1975; Yeh \& Ornston, 1981; Shanley et al., 1986; Hughes et al., 1988; Entsch et al., 1988; Van Berkel et al., 1992) and

The GenBank accession number for the sequence data reported in this paper is L23969.
Acinetobacter (Neidle \& Ornston, 1986; Doten et al., 1987; Hartnett et al., 1990; Neidle et al., 1991; DiMarco et al., 1993a, b), little is known about the systems involved in the entry into the cell of aromatic intermediates of this pathway. Although the presence of an uptake permease for 4-hydroxybenzoate (and other aromatic substrates) has been assumed for Rbizobium (Chen et al., 1984; Wong et al., 1991) as well as for other bacteria such as Pseudomonas spp. (Entsch et al., 1988), there has been no unequivocal demonstration of such a permease. A benzoate permease has been reported in Pseudomonas putida (Thayer \& Wheelis, 1982), but the question of whether 4hydroxybenzoate enters rhizobia by diffusion (as originally assumed for Pseudomonas; Rottenberg, 1975; Thayer \& Wheelis, 1982), or via a permease (as suggested by Chen et al., 1984; Wong et al., 1991) remains unanswered.

We have previously suggested (Wong $e t$ al., 1991) that there are separate uptake systems for entry of 4hydroxybenzoate and protocatechuate into $R$. leguminosarum and $R$. trifolii, and that these substrates gain entry into the cell via an active transport system. The major evidence for this came from the finding that ${ }^{14} \mathrm{C}$ accumulation by $R$. leguminosarum MNF300 from 4hydroxy $\left[{ }^{14} \mathrm{C}\right]$ benzoate was markedly decreased by metabolic inhibitors and by other hydroxyaromatic compounds. The detection of 4-hydroxybenzoate hydroxylase 
Table 1. Bacterial strains and plasmids

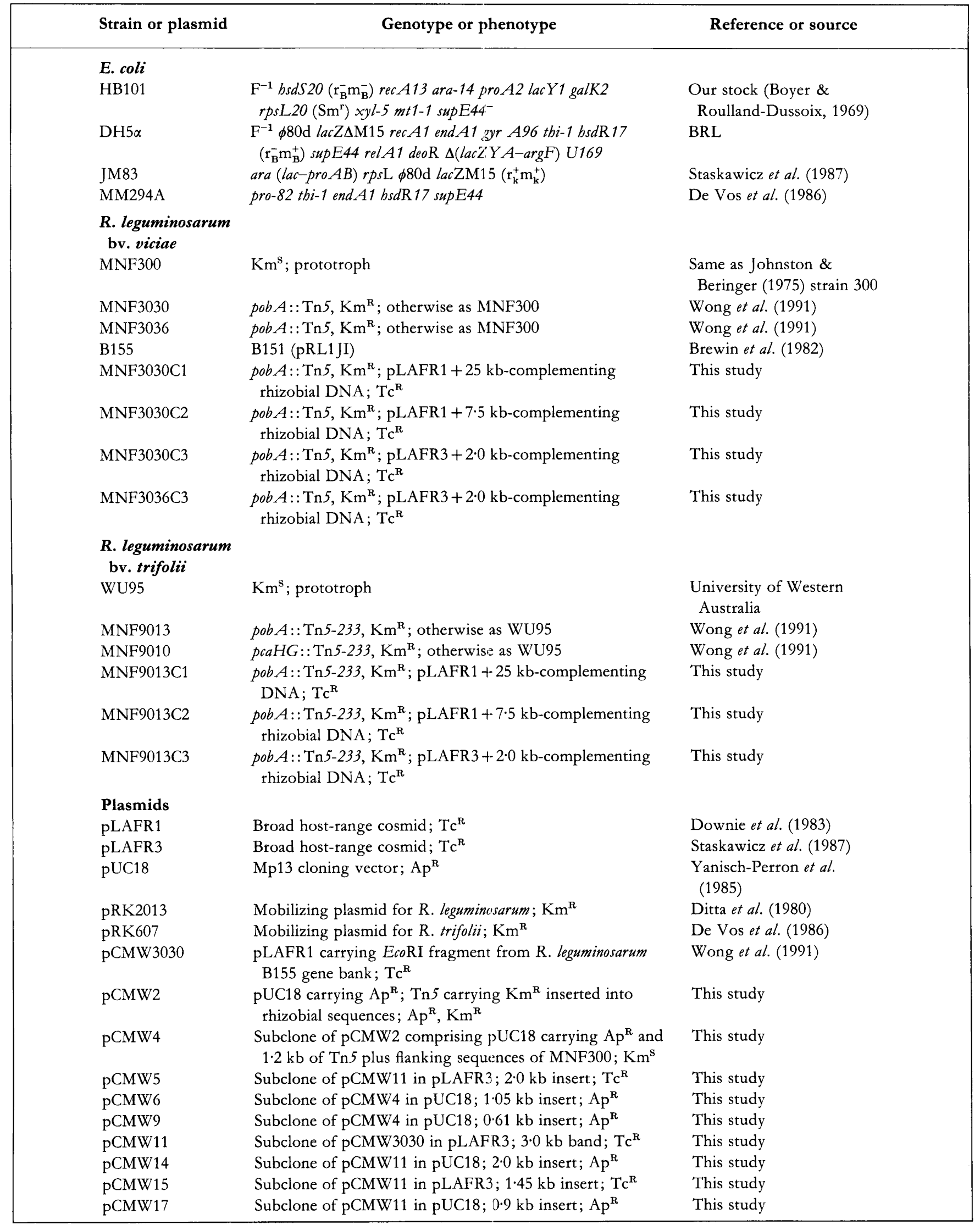




\begin{tabular}{|lll|}
\hline Strain or plasmid & \multicolumn{1}{c|}{ Genotype or phenotype } & Reference or source \\
\hline pCMW18 & Subclone of pCMW11 in pUC18; $1.1 \mathrm{~kb}$ insert; $A \mathrm{p}^{\mathrm{R}}$ & This study \\
pCMW21 & Subclone of pCMW17 in pUC18;0.17 kb insert; Ap ${ }^{\mathrm{R}}$ & This study \\
pCMW22 & Subclone of pCMW17 in pUC18;0.72 kb insert; Ap ${ }^{\mathrm{R}}$ & This study \\
pCMW23 & Subclone of pCMW18 in pUC18;0.66 kb insert; A $\mathrm{p}^{\mathrm{R}}$ & This study \\
pCMW24 & Subclone of pCMW18 in pUC18;0.48 kb insert; $\mathrm{p}^{\mathrm{R}}$ & This study \\
pCMW30 & Subclone of pCMW14 in pUC18;0.64 kb insert; Ap & This study \\
\hline
\end{tabular}

in a mutant of $R$. trifolii WU95 (MNF9013) that could grow on protocatechuate and 4-hydroxymandelate, but not on 4-hydroxybenzoate, implied that the lesion in this mutant should be in a 4-hydroxybenzoate permease (Wong et al., 1991).

The mechanism of 4-hydroxybenzoate uptake has now been re-examined by cloning and sequencing of the gene involved in uptake of this solute. This paper presents evidence that 4-hydroxybenzoate hydroxylase is required for continued entry of 4-hydroxybenzoate into cells of $R$. leguminosarum.

\section{METHODS}

Bacteria and plasmids. The bacteria and plasmids used in this study are listed in Table 1 . Wild-type rhizobial strains MNF300 and WU95 are able to grow on 4-hydroxybenzoate or protocatechuate as sole carbon source. Mutants MNF3030, MNF3036 and MNF9013 are unable to grow on 4-hydroxybenzoate but can grow on protocatechuate. The protocatechuate 3,4dioxygenase mutant MNF9010 is unable to grow on 4hydroxybenzoate or protocatechuate.

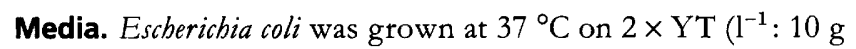
yeast extract, $16 \mathrm{~g}$ tryptone and $5 \mathrm{~g} \mathrm{NaCl}$ ). Rhizobial strains were grown at $28^{\circ} \mathrm{C}$ in minimal salts medium (MS; Brown \& Dilworth, 1975) containing $40 \mathrm{mM}$ HEPES, $\mathrm{pH} 7 \cdot 0$ (MSH), $\mathrm{NH}_{4} \mathrm{Cl}(10 \mathrm{mM}), 0.3 \mathrm{mM}$ potassium phosphate and 5 or $10 \mathrm{mM}$ glucose or $2 \mathrm{mM}$ 4-hydroxybenzoate. Complemented and other rhizobial mutants were cultivated and maintained on media containing $12.5 \mu \mathrm{g}$ tetracycline $\mathrm{ml}^{-1}$ or $50 \mu \mathrm{g}$ kanamycin $\mathrm{ml}^{-1}$, respectively.

Plasmid mobilization and complementation. A cosmid library of R. leguminosarum B155 genomic DNA was kindly supplied by Dr J. A. Downie of the John Innes Institute, Norwich, UK. Plasmid transfer from E. coli to Rbizobium sp. was by triparental matings on TY medium using HB101 or J53 carrying pRK2013 or pRK607, respectively.

Isolation of chromosomal and plasmid DNA, and transformations. Total DNA was prepared from mid-exponential or stationary phase cultures of strains grown in $5 \mathrm{ml}$ TY medium (supplemented with kanamycin when appropriate) by the method of Ausubel et al. (1988). Plasmid DNA was isolated on a $\mathrm{CsCl}$ gradient as described by Sambrook et al. (1989). Minipreparations of plasmid DNA were extracted by the alkaline lysis method of Sambrook et al. (1989) and transformed into $E$. coli using the method of Hanahan et al. (1991).

Probe preparation. DNA probes were isolated on low-meltingtemperature (LMT) agarose, purified by gelase (supplied by Epicentre) or on Magic PCR columns (Promega Corp) and labelled with biotin or digoxygenin 11-dUTP according to the manufacturer's (Bresatec) instructions.

DNA hybridizations. Denatured, neutralized, membrane-bound DNA was added to hybridization fluid. Hybridizations were carried out at $68^{\circ} \mathrm{C}$ (high stringency) and $28^{\circ} \mathrm{C}$ (low stringency) and washes were as described by Sambrook et al. (1989).

Subcloning of complementing plasmid. Plasmid pCMW 3030 was digested with EcoRI, religated and transformed into E. coli HB101. Tetracycline-resistant transformants were filter-mated separately to R. leguminosarum MNF3030 and MNF3036 and R. trifolii MNF9013 and colonies selected for growth on 4hydroxybenzoate.

A $2.0 \mathrm{~kb}$ EcoRI-Pst I and a $1.45 \mathrm{~kb}$ internal Pst $\mathrm{I}$ contiguous fragment were subcloned into EcoRI-Pst I- or Pst I-cut PLAFR3 to form $\mathrm{pCMW} 5$ and $\mathrm{PCMW15}$, respectively. These plasmids were used in complementation experiments and in further subcloning for DNA sequence analysis.

Cloning and subcloning of sequences flanking Tn5. EcoRIdigested genomic DNA from MNF3030 was ligated into pUC18 and transformed into E. coli JM83; transformants were selected on $2 \times$ YT plus kanamycin and ampicillin. A plasmid, pCMW2 (approximately $22 \mathrm{~kb}$ ), was isolated from two transformants and subcloned into $\mathrm{DH} 5 \alpha$.

Nucleotide sequence analysis. DNA sequencing was performed using the Prism Ready Reaction kit and automated sequencer from Applied Biosystems. Analysis of sequence data was performed using the MacVector computer program.

Recrystallization of hydroxymandelate. 4-Hydroxymandelate (Sigma) was dissolved in ethyl acetate, decolorized with Norit A charcoal, and crystallized by the gradual addition of an equal volume of petroleum ether.

Growth experiments. Wild-type and complemented rhizobial strains were grown with shaking at $28^{\circ} \mathrm{C}$ to mid-exponential phase in MSH containing $2 \mathrm{mM}$ 4-hydroxybenzoate; a similar medium containing $2 \mathrm{mM}$ 4-hydroxymandelate was used to determine whether these strains could grow on 4hydroxymandelate. The mutants were grown in similar medium but with the addition of 5 or $10 \mathrm{mM}$ glucose. Cultures were harvested, washed twice in minimal salts and resuspended in $1 \mathrm{mM} 4$-hydroxybenzoate or $1 \mathrm{mM}$ 4-hydroxymandelate as sole carbon source and cell density monitored.

4-Hydroxybenzoate or 4-hydroxymandelate consumption. Cells were grown essentially as described above and resuspended to an $A_{600}=0.1-0.5$ in $\mathrm{MSH}$ containing $1 \mathrm{mM}$ hydroxybenzoate or $1 \mathrm{mM}$ 4-hydroxymandelate as the sole carbon source (except where stated otherwise). Samples were removed every 1.5 or $2.0 \mathrm{~h}$ for measurement at $A_{600}$ and for assay of the concentration of 4-hydroxybenzoate or 4hydroxymandelate. The rate of substrate disappearance was 
Table 2. Mean generation times for growth on 4-hydroxybenzoate, rates of consumption of 4-hydroxybenzoate and rates of transport of 4-hydroxy $\left[{ }^{14} \mathrm{C}\right]$ benzoate for strains of $R$. leguminosarum and $R$. trifolii

The number of replicates is shown in parentheses. Replicates differed by no more than $30 \%$. No antibiotics were used for growth experiments.

\begin{tabular}{|c|c|c|c|c|}
\hline Strain & $\begin{array}{c}\text { Complementing } \\
\text { plasmid }\end{array}$ & $\begin{array}{l}\text { Mean generation } \\
\text { time }(h) \text { on } \\
\text { 4-hydroxybenzoate }\end{array}$ & $\begin{array}{c}\text { Rates of } \\
\text { consumption of } \\
\text { 4-hydroxybenzoate } \\
{\left[\mu \mathrm{mol} \mathrm{h} \mathrm{h}^{-1}\right.} \\
\left.\left(A_{600}\right)^{-1}\right]\end{array}$ & $\begin{array}{c}\text { Uptake of } \\
\text { 4-hydroxy }\left[{ }^{14} \mathrm{C}\right] \text { benzoate } \\
{\left[\text { nmol min }{ }^{-1}\right.} \\
\left.(\mathrm{mg} \text { protein })^{-1}\right]\end{array}$ \\
\hline MNF300 & - & $8 \cdot 0-9 \cdot 0(4)$ & $0.66(2)$ & $28 \cdot 5(3)$ \\
\hline MNF3030 & - & No growth & 0 & 0 \\
\hline $\begin{array}{l}\text { MNF3030C1 or } \\
\text { MNF3030C2 }\end{array}$ & $\begin{array}{l}\text { PCMW3030 or } \\
\text { pCMW11 }\end{array}$ & $15 \cdot 0-16 \cdot 0(2)$ & $0 \cdot 37(2)$ & $5 \cdot 5(2)$ \\
\hline MNF3036 & - & No growth & 0 & 0 \\
\hline $\begin{array}{l}\text { MNF3036C1 or } \\
\text { MNF3036C2 }\end{array}$ & $\begin{array}{l}\text { pCMW3030 or } \\
\text { pCMW11 }\end{array}$ & $19 \cdot 0-20 \cdot()(2)$ & $0 \cdot 3(2)$ & $6 \cdot 3(2)$ \\
\hline WU95 & - & $4.5 \pm 0.5(5)$ & $0.88(2)$ & $25 \cdot 5(2)$ \\
\hline MNF9013 & - & No growth & 0 & 0 \\
\hline $\begin{array}{c}\text { MNF9013C1 or } \\
\text { MNF9013C2 }\end{array}$ & $\begin{array}{l}\text { pCMW3030 or } \\
\text { pCMW11 }\end{array}$ & $6 \cdot 0-7 \cdot 0(2)$ & $0 \cdot 66(2)$ & $25 \cdot 0(2)$ \\
\hline
\end{tabular}

determined by plotting substrate concentration against $\int A_{600} \cdot \mathrm{dt}$ (Dilworth et al., 1983).

\section{Uptake of 4-hydroxy[ $\left.{ }^{14} \mathrm{C}\right]$ benzoate and $\left[{ }^{14} \mathrm{C}\right]$ protocatechuate. Uptake of 4-hydroxy[7- $\left.{ }^{14} \mathrm{C}\right]$ benzoate (Amersham) was measured as described by Wong et al. (1991). [ $\left.{ }^{14} \mathrm{C}\right]$ Protocatechuate was prepared and its uptake measured as described by Wong et al. (1991).}

Analytical methods. 4-Hydroxybenzoate was measured in culture supernatants by acidifying with $\mathrm{HCl}$ (to $0.1 \mathrm{M}$ final concentration) and recording $A_{255}$. Concentration was calculated using an absorption coefficient of $14560 \mathrm{M}^{-1} \mathrm{~cm}^{-1}$ at $255 \mathrm{~nm}$. 4-Hydroxymandelate was assayed at $234 \mathrm{~nm}$. Protein was determined using the method of Lowry with bovine serum albumin as a standard.

Paper chromatography. Hydroxyaromatic compounds were chromatographed and detected as described by Smith (1960).

Enzyme assays. Cell-free extracts were prepared as described by Wong et al. (1991) and 4-hydroxybenzoate hydroxylase was assayed using the method of Entsch et al. (1976). 4Hydroxybenzoate, protocatechuate, 4-hydroxybenzaldehyde, 2,5-dihydroxybenzoic acid and carbonyl cyanide- $m$ chlorophenyl hydrazone (CCCP) were supplied by Sigma.

\section{RESULTS AND DISCUSSION}

\section{Complementation of mutants}

Following conjugation with a cosmid library of $R$. leguminosarum B155 DNA in E. coli, one plasmid (pCMW3030) was identified which enabled MNF3030 to grow on 4-hydroxybenzoate. A $4.0 \mathrm{~kb}$ EcoRI fragment subcloned from pCMW3030 (to form pCMW11) and a $2.0 \mathrm{~kb} E c o \mathrm{RI}-P s t \mathrm{I}$ subclone of it (pCMW5) enabled the mutants MNF3030, MNF3036 and MNF9013 to grow on 4-hydroxybenzoate as sole source of carbon.
Complemented mutants of $R$. leguminosarum grew slowly on 4-hydroxybenzoate, whereas the complemented mutant of R. trifolii was more like the wild-type (Table 2). A direct quantitative comparison of growth rates of complemented strains with those of the wild-types is not valid as a wild-type containing the cloning vector was not constructed. The rate of consumption of 4hydroxybenzoate and growth on it appeared to be correlated in the complemented strains.

\section{Restriction mapping}

The $4.0 \mathrm{~kb}$ complementing DNA from $\mathrm{R}$. leguminosarum B155 was restriction-mapped using the fragments shown in Fig. 1(a) as hybridization probes. This $4.0 \mathrm{~kb}$ fragment was used as a probe against EcoRI-digested genomic DNA from MNF300, MNF3030 and WU95. DNA from MNF300 showed two hybridizing bands $(1.8 \mathrm{~kb}$ and $2.2 \mathrm{~kb}$ ) and there were bands at $0.3 \mathrm{~kb}, 1.5 \mathrm{~kb}$ and $2.2 \mathrm{~kb}$ in WU95, indicating that DNA from these strains contain additional EcoRI sites not found in B155. DNA from the Tn5-induced mutant, MNF3030, showed bands of $2 \cdot 2 \mathrm{~kb}$ and $7.6 \mathrm{~kb}$, indicating that $\operatorname{Tn} 5$ had inserted into the $1.8 \mathrm{~kb}$ EcoRI fragment.

The sequences flanking $\operatorname{Tn} 5$ in MNF3030 were cloned and mapped (Fig. 1a). A $0.55 \mathrm{~kb}$ probe (see Fig. 1b) hybridized to the $1.8 \mathrm{~kb}$ fragment from MNF300 and the $7.6 \mathrm{~kb}$ fragment of MNF3030. The region of insertion of Tn 5 in MNF3030 was determined using this probe against the $4 \cdot 0-\mathrm{kb}$-complementing B155 DNA digested with $B g / \mathrm{I}$ (Fig. 1b).

The $2.0 \mathrm{~kb}$ EcoRI-PstI fragment of the $4.0-\mathrm{kb}$ complementing B155 DNA (Fig. 1a) was subcloned and 
(a)

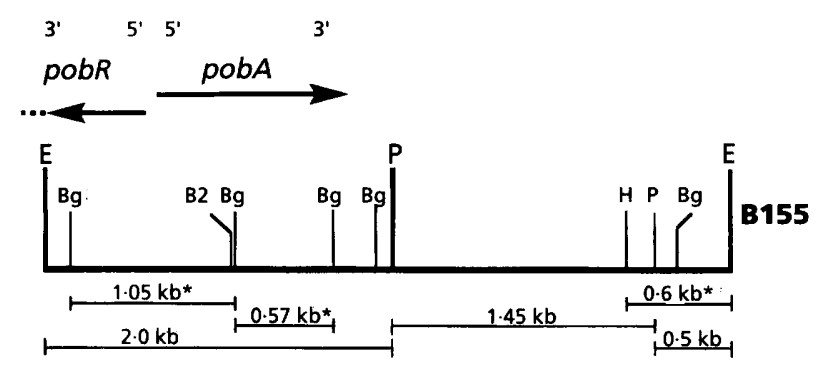

(b)
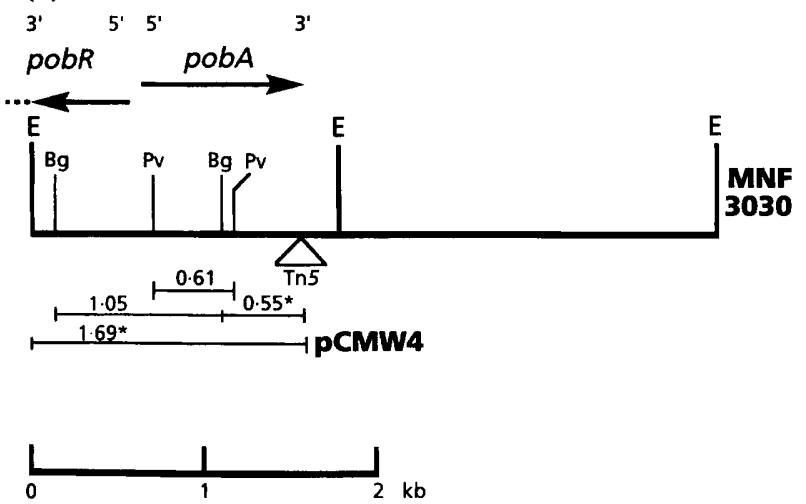

Fig. 1. (a) Restriction map of the $4.0 \mathrm{~kb}$ fragment isolated from $R$. leguminosarum B155 able to complement mutants of $R$. leguminosarum MNF300 and $R$. trifolii WU95. There were no sites for BCll, HindllI, Haell, Kpnl, SaCl or Xhol. The isolated $4.0 \mathrm{~kb}$ fragment was digested with restriction enzymes (Bg/l, Hpal, and Pstl) and fragments marked with an asterisk used as probes against EcoRI genomic DNA digests of wild-type and mutant DNAs plus the $4.0 \mathrm{~kb}$ fragment digested separately with $B g / l$ and Pstl. The $2.0 \mathrm{~kb}$ EcoRI-Pstl fragment was subsequently shown to also complement the Tn5 mutants. The extent of sequence data for pobA and pobR is indicated by arrows over the $2.0 \mathrm{~kb}$ fragment. The map is aligned with the equivalent region in MNF300. (b) Restriction map of pCMW4 isolated from the 4-hydroxybenzoate-negative mutant pCMW3030 showing IS sequences from Tn5 flanking $1.55 \mathrm{~kb}$ of rhizobial DNA in pUC18. The two probes $(0.55 \mathrm{~kb}$ and $1.69 \mathrm{~kb})$ marked with an asterisk were hybridized against EcoRI-digested genomic DNA of MNF300 and plasmids pCMW5 ( $1.45 \mathrm{~kb}$ of B155 DNA), pCMW15 (2.0 kb of B155 complementing DNA) plus the Bg/ldigested $2.0 \mathrm{~kb}$ complementing DNA from B155. The extent of sequence data for pobA and pobR is indicated by arrows over sequences flanking Tn5. Bg, Bgll; B2, Bg/lI; E, ECoRI; H, Hpal; P, Pstl; Pv, Pvul.

found to complement the mutants. This indicated that the defective gene was located within this fragment.

\section{DNA sequencing}

The DNA sequence was determined by sequencing both strands of overlapping cloned fragments from the $2.0 \mathrm{~kb}$ (B155) and $1.55 \mathrm{~kb}$ (MNF300) fragments of DNA, using synthetic primers where appropriate.

Analysis of the sequence data revealed three ORFs comprising at least 300 nucleotides within the $2 \cdot 0 \mathrm{~kb}$ fragment, but only one of substantial length $(1.17 \mathrm{~kb})$. A second ORF $(0.43 \mathrm{~kb})$ is transcribed upstream and in the opposite direction to the largest. Another small ORF of $0.51 \mathrm{~kb}$ (transcribed in the opposite direction to the $1.17 \mathrm{~kb}$ ORF) is found in the centre of the major ORF but does not possess sequences necessary for transcription. The $1.17 \mathrm{~kb}$ ORF sequence showed substantial similarity only to the 4-hydroxybenzoate hydroxylase $(p o b A)$ genes of $P$. aeruginosa (Entsch et al., 1988, accession M23173), $P$. fuorescens (Van Berkel et al., 1992, accession L13747) and A. calcoaceticus (DiMarco et al., 1993a, accession L03407).

The DNA sequence of the $R$. leguminosarum $p o b A$ gene from $R$. leguminosarum B155 is shown in Fig. 2(a). The gene has 1173 nucleotides (390 amino acids, beginning with leucine). The $5^{\prime}$ end of the transcribed gene sequence was immediately preceded by the ribosome-binding sequence GGAGG, separated by six residues from the translational start. Just after the $\mathrm{C}$ terminus of the protein, a stem-loop structure 5' CGAGGATAATTCTGC ATCCTCG $3^{\prime}$ was detected (Fig. 2a).

DNA from the homologous region in $R$. leguminosarum MNF300 (flanking Tn5 in pCMW4) was partially sequenced (Fig. 2b; 936 nucleotides and 312 corresponding amino acids). Tn 5 had inserted $0.94 \mathrm{~kb}$ from the beginning of the gene. The pob $A$ gene for both strains begins with a leucine codon and is preceded by the ribosome-binding sequence GGAGG.

\section{Homology of $\boldsymbol{R}$. leguminosarum pobA}

About $80 \%$ of the $p o b A$ gene in MNF300 has been sequenced. The nucleotide sequences of $p 0 b A$ from MNF300 and B155 show 93\% homology (over 936 nucleotides). The MNF300 protein differs from that from B155 by 15 residues (Fig. 3).

Comparison of the $p o b A$ sequences from $R$. leguminosarum $\mathrm{B} 155$ and $P$. aeruginosa and $P$. fluorescens (Entsch et al., 1988 ) indicated $66 \%$ nucleotide identity and $64 \%$ amino acid identity. The $p o b A$ identity of $P$. aeruginosa with $R$. leguminosarum MNF300, over the 312 amino acids for which sequence has been determined, was $69 \%$ (cf $68 \%$ with $\mathrm{B} 155$ for the same residues). The regions associated with substrate and FAD binding are the most highly conserved (Fig. 3). The eight amino acids that have been shown to have a substrate-binding function in the $P$. aeruginosa PobA show $100 \%$ identity in both B155 and MNF300, while the 21 amino acids associated with FAD binding in $P$. aeruginosa PobA show $95 \%$ identity (Fig. 3). In particular, Tyr201 and Tyr385 (which in PobA from $P$. aeruginosa and $P$. fuorescens interact with the 4-hydroxy residue in the substrate; Van Berkel et al., 1992), have been conserved in the same relative positions in $R$. leguminosarum, as have Ser212, Arg214 and Tyr222, which interact with the carboxyl moiety of the substrate.

Alignment of the derived amino acid sequences of PobA from $R$. leguminosarum and $A$. calcoaceticus revealed $60 \%$ identity (Fig. 3). The Acinetobacter protein (DiMarco et al., 1993a) comprises 401 amino acids and appears to lack a residue somewhere between the completely conserved amino acids at position 131 (Asp) and position 137 (Pro) 
(a)

CAGCCGCCTCAACGTCTGCATGACATAGGCTGCCTCGGCATGATCGGGATCGAGCGGCGTCAGATGCGGGCCGCCAACCATTCGCCGAGCTGGCTTCGG

TCGCCGGGCGGATGGCTGAGATGGGATCTCAACAGGGTGATCACCAGGCCGTCGATATCGCGTGAAAAACGAAAGCCGTGATTGAGCCCGGGCGGCACGG TGATGATGGCCGGCGGACGGATGGCATGGCTCTTTTCGCCGAAAATCGCATCGCCCGAACCGCTTTCGATGTACAATATCTGAAAGAAACTCTCGTGGCG GTGCGGGCGAATCTCCCAGTGATGCAAACTGCTGCGAGAGCGAATTGTTTCGCAATGCACCCAAAAATCCGGTTCTCGCCCGGTCTTTTCGCCGTAGAGT TCATAGGTAGGGACCTGTCTGCTCATGGGGCRCCGTGGGGCTTCGCCGACACCAATGTTCGATTAGTGCAATWTAAGGTCGGCATGTCCATTGCTGCGG RBS $-35$ $-10$ CAAGCGCGGCACGGCAGAATCTGACAAAACGCAAAAATGCAGGGAGGCAGCATTTGCGAACTCAGGTCGCCATCATCGGTTCGGGGCCATCCGGCCTGCT RBS GCTCGGCCAGCTTCTGACCGAAGCCGGCATCGACAATGTCATCCTCGATCGTGTGAACAAGGATTACATCCTCGGCCGGGTTCGTGCCGGCGTTCTGGAG GAAGGCACCGTCGGGCTGTTGGATCAGGCCAGATCAGGCGCGAGGCTGCATGCCGAGGGGCTGCCGCATGACGGTTTCTCGCTGGCCTTCGACGGACGCG ACCATCGCATCGACCTTCACGAATTGACCGGCGGCAGGCGCGTCACCGTCTACGGACAGACCGAAGTGACGCGCGATCTCATGGAGCGGCGCGAAGAAAG CGGCTCCTTATCGATCTACGATGCCGTCGACGTCGCACCGCATGACTTCGACGGCCCTTCTCCCTTCGTCACCTATGTGAAAGACGGTGTTGCCAAGCGC ATCGATTGTGACTTCATCGCCGGCTGCGACGGGTTTCACGGCGCCAGCCGCAAGGCCGTCCCGGAACGGGCGATCAGGAGTTTCGAGAAGATCTATCCCT TCGGCTGGCTGGGGATCCTTGCCGACGTGGCGCCTGTCAGCCATGAACTCATCTACGCCAACCATCCAAGGGGCTTTGCGCTCTGTTCGATGCGCTCGGC CACCCGCAGCCGCTACTACATCCAATGTACGCTCGACGAGAAAATCGATCACTGGAGCGACGATCGCTTCTGGGACGAGTTGAGACGGCGGCTGCCGACG CATCATGCCGAGGCATTGGCGACCGCGCCGTCCTTCGAGAAATCGATTGCGCCGCTGCGCTCCTTCGTTGCCGAACCGATGCGTTTCGGCCGGCTTTTCC TGGTCGGCGACGCTGCCCATATCGTCCCGCCGACCGGGGCCAAGGGATTAAACCTTGCCGCCAGCGACGTCCATTACCTTTTCTCCGGGCTGATCGAGCA TTACCGCGAAGGCTCGAATAGTGGCATTGACGCTTACTCGCATAAGGCGC TCGCCCGTGTGTGGAAAGCCGTGCGGTTTTCCTGGTGGATGACGACGATG ATGCATCTTTTTCCGGATACCGGTGATTTCGACCAGAAAATCCAGGAGGCGGAGCTCGACTATCTCACCCATTCCCGCGCCGCCTCGATGGCGCTCGCGG AGAATTATGTGGGATTACCATTCTGAGACGAGgATAATTCTGCATCCTCGATGCACAATCATAATCGCCAGGTCATGGATTACGGCATTTATTTCATTTT -...-Terminator-...... ACATCACCATTTCGCATGACAAGCTAACGCTCAAGATTTTGGGCGGCTAC CGAATACGGCGCGGGAGTGCGCCAAAAAGGGAGAGAGAATGAAGAAGCTA TTTCTAGCCGCCGTTGCGGCCGTCGTGCTCAGCGGCACGGCCTATGCAGACACCATCAAGGTCGGCGTCATCGGCCCGTTACTCCGGTCCGTTCGC

(b) GTCGCCCAGCCGCTCCAACGTCTGCATGACATAGGCTGCCTCGGCATTA'ZGCGATCGAGCGGCGTCAGATGCGGCGTAGCAAACCATTCGCCGAGATGG CTTCGCTCGCCGGGCGGATGGCTGAGATGGGATCTCAACAGGGTGATCACCAGGCCGTCGATATCGCGTGAAAAACGAAAGCCGTGATTGAGACCGGGCG GCACAGTGATGATGGCCGGCGGACGGATGGCGTGACTTTTTTCGCCGAACATCGCATCACCCGAACCGCCTTCAATGTACAATATCTGAAAGAAACTCTC GTGACGGTGCGGACGAATCTCCCATTGATGCAAGCTGCTGCGAGAGCGAATTGTTTCGCAATGCACCCAAAAATCCGGTTCTCGCCCGGTCTTT'TCGCCG TAGAGTTCATAGGTAGGGACCTGTCTGCTCATGGGGTTCCGTGGGGTTTCTTCGGAMTCAATGTTCGATTAGTGCAATHTATAGGTTGGGATGTCCATTG T"TGCGGCAAGCGCGACACGGCAGAATCTGGAAAAACGCAAAAATGCAGggGaggaGCATTTGCGAACTCAGGTCGCCATCATCGGTTCGGGACCCTCCG RBS GCCTGTTGTTCGGCCAGCATCTGACCGAAGCCGGCATCGAGAATGTCAT:CTCGATCGTGTGAACAAGGATTACATCCTCGGCCGGGTTCGTGCCGGCGT TCTGGAGGAAGGCACCGTTGGGCTGCTGGATCAGGCAAAAGCCGGGACGCGGCTACATGCCGAGGGCCTGCCGCATGACGGTTTCTCATTGGCCTTCGAC GGACGCGACCATCGCATTGACCTCCACGAATTGACCGGCGGCAGACGCG'TGACGGTTTATGGACAGACCGAAGTGACGCGCGATCTCATGGAGCGGCGTG AAGCGAGCGGCTCCCTGTCGATCTACGATGCCGTCGATGTCGCGCCGCATGATTTCGACGGCCACTCTCCCTTCGTCACCTATGTGAAAGATGGTGTTGC CAAGCGCATCGATTGCGACTTCATCGCCGGCTGCGACGGGTTTCACGGCITCAGCCGCAAGGCCGTCCCGGAACGGGCGATCAGGAGTTTCGAGAAGGTC 1103

TATCCCTTCGGCTGGCTGGGGGTCCTTGCCGACGTGGCGCCTGTCAGTCATGAACTGATCTACGCCAACCATCCAAGGGGCTTTGCGCTCTGTTCGATGC GCTCGGCGACCCGCAGCCGCTACTACATCCAATGCGCGCTCGACGAGAAİATCGAGAACTGGAGCGACGATCGCTTCTGGGACGAGTTGAGACGGCGTCT GCCGGTGCATCACGCCGAGGCCTTGCCGACCGCGCCGTCCTTCGAGAAA'TCGATCGCGCCGCTGCGCTCCTTCGTCGCCGAACCGATGCGTTTCGGCCGG CTTTTCCTGGTCGGCGACGCCGCCCATATCGTCCCGCCGACCGGCGCCAגGGGACTGAACCTTGCCGCCAGCGACGTTCATTATCTTTTCTCCGGGCCTG

Fig. 2. (a, b). For legend see facing page. 
present in both $R$. leguminosarum strains and in the Pseudomonas spp. Additional residues are found at the $\mathrm{C}$ terminus of the Acinetobacter protein. Again, regions associated with substrate and FAD binding are highly conserved.

Both the Pseudomonas PobA proteins comprise 394 amino acids (Entsch et al., 1988; Van Berkel et al., 1992) compared with 390 in the R. leguminosarum PobA; the four extra residues in the Pseudomonas enzyme are found at the $\mathrm{C}$ terminus.

As in Pseudomonas (Entsch et al., 1988), there is a high $\mathrm{G}+\mathrm{C}$ content in the coding portion of the $R$. leguminosarum gene (61\% vs $68 \%$ in Pseudomonas) and the codons are dominated by $\mathrm{C}$ and $\mathrm{G}$ in the third (degenerate) position ( $75 \%$ in $R$. leguminosarum vs $90 \%$ in $P$. aeruginosa). The preference for $\mathrm{G}$ and $\mathrm{C}$ in the first (codon) position in the $P$. aeruginosa pobA $(69 \%)$ also occurs in the $R$. leguminosarum gene $(63 \%)$.

Whilst there is identity of more than $99 \%$ between the PobA amino acid sequences in different species of Pseudomonas ( $P$. aeruginosa and $P$. fluorescens), identity of these sequences between Rbizobium strains (B155 and MNF300) is less (95\% for $80 \%$ of the coding portion of the gene). More variation was revealed when a probe of $0 \cdot 17 \mathrm{~kb}$ isolated from the $\mathrm{R}$. leguminosarum $\mathrm{B} 155$ pob $A$ gene (in a region associated with substrate binding in Pseudomonas) was hybridized against genomic DNA from other strains and species of Rbizobium. Other strains of $R$. leguminosarum bv. viciae (WSM710, SU391) showed a band of the same $(1.8 \mathrm{~kb})$ or similar size to that in MNF300 (although 710 showed a single fragment of $3.8 \mathrm{~kb}$ ), but different strains of Rhizobium (including $R$. trifolii, $R$. phaseoli and $R$. meliloti) and other species ( $P$. aeruginosa) revealed genomic EcoRI fragment(s) sizes ranging from $0.3 \mathrm{~kb}$ to $6.7 \mathrm{~kb}$.

\section{Promoter and operator regions of pobA in $R$. leguminosarum}

The similarities between pob $A$ from $R$. leguminosarum and $P$. aeruginosa do not extend to the promoter and operator regions. Whilst the consensus ribosome-binding site (RBS) in P. aeruginosa, 5' GAGG 3' found 10 bp upstream from the start codon (Entsch et al., 1988), is similar to that found in $R$. leguminosarum, the operator palindrome sequence (of $21 \mathrm{bp}$ ) found $29 \mathrm{bp}$ upstream from the $P$. aeruginosa start codon is not found in $\mathrm{R}$. leguminosarum. No palindromic sequences are found in this region in either R. leguminosarum B155 or MNF300.

A feature of the regulatory region of $p \circ b A$ in $P$. aeruginosa is the occurrence of $\mathrm{A}+\mathrm{T}$-rich regions in a gene which overall is $68 \% \mathrm{G}+\mathrm{C}$. In $R$. leguminosarum (B155 and $\mathrm{MNF} 300$ ) the regions upstream of the start codon also contain regions which are $\mathrm{A}+\mathrm{T}$-rich in comparison with the $\operatorname{pob} A$ gene. Specifically, the sequence $5^{\prime}$ AATTTT $3^{\prime}$ (in B155) and 5' TTTATA $3^{\prime}$ (in MNF300) occur in the same position upstream of the start codon as the -10 site in $P$. aeruginosa (Fig. $2 \mathrm{a}$ and $\mathrm{b}$ ). Both of these putative -10 sites occur in the regulatory region at the richest $A+T$ sites. Similarly, the putative -35 sites in $R$. leguminosarum, $5^{\prime}$ CCGACA 3' (B155 and 5' GGAA'TC 3' (MNF300), are found 18 bases upstream from their respective -10 sites (Fig. $2 \mathrm{a}$ and $\mathrm{b}$ ). Neither of the proposed -10 and -35 sites (nor any regions nearby) show similarity with promoter sites for other Rhizobium genes (Gray et al., 1990; Bae \& Stauffer, 1991; De Maagd et al., 1992). Sequences found in similar positions upstream of the start codon for pob $A$ in $A$. calcoaceticus (DiMarco et al., 1993b) do, however, show similarity to these putative promoter sites in $R$. leguminosarum. The sequence $5^{\prime}$ AATTTT $3^{\prime}$ occurs in the same $(-10)$ region in $A$. calcoaceticus.

The -35 site in A. calcoaceticus, 5' GACAGG $3^{\prime}$ (DiMarco et al., 1993b), shows little similarity to the putative -35 sites in R. leguminosarum B155 and MNF300, although the B155 site does show three matches of six to the E. coli $\sigma^{70}$ consensus sequence 5' TTG ACA 3' (Harley et al., 1987). Sequence dissimilarity in the -35 region is not uncommon in positively regulated promoters (Raibaud \& Schwartz, 1984).

The putative -10 site for $R$. leguminosarum MNF300 ( $5^{\prime}$ TTTATA $3^{\prime}$ ) is identical to part of a possible integration host factor (IHF)-binding site proposed for a RopA (repressed outer membrane) protein of $R$. leguminosarum (De Maagd et al., 1992).

\section{Regulation of pobA in R. leguminosarum}

A transcriptional activator ( $p \circ b \mathrm{R})$ was recently described for pobA in $A$. calcoaceticus (DiMarco et al., 1993b). Inducible expression of cloned $p o b A$ in $E$. coli depended on the presence of a functional $p o b R$. Regions upstream of the $R$. leguminosarum $p o b A$ (B155 and MNF300) were

Fig. 2. (a) Sequence data obtained for the $2.0 \mathrm{~kb}$-complementing DNA from $R$. leguminosarum $B 155$ comprising the gene for 4-hydroxybenzoate hydroxylase $(p o b A)$ and its putative positive transcriptional regulator (pobR). The sequence for pobA in the $5^{\prime}-3^{\prime}$ direction begins at nucleotide 602 . The sequence for pobR is shown in the $3^{\prime}-5^{\prime}$ orientation with the initiator codon for the amino-terminal amino acid of the protein beginning at nucleotide 474 . The last digit of each number identifies the exact nt which corresponds to that number. The nucleotide sequences highlighted above 'terminator' delineate a palindromic sequence associated with termination of transcription of pobA. The sequences above RBS correspond with those attributed to the ribosome-binding sites. Putative promoter regions -10 and -35 upstream of the pobA RBS are also highlighted. (b) Partial nucleotide sequence for the pobA/pobR region from MNF300. The sequence for pobA in the $5^{\prime}-3^{\prime}$ direction begins at nucleotide 563 and extends to the site of insertion of Tn5 (highlighted). The sequence for $p o b R$ is shown in the $3^{\prime}-5^{\prime}$ orientation with the initiator codon for the amino-terminal amino acid of the protein beginning at nucleotide 435. The sequence above RBS corresponds with that attributed to the ribosome-binding site for pobA. Putative promoter regions -10 and -35 upstream of the pobA RBS are also highlighted. 


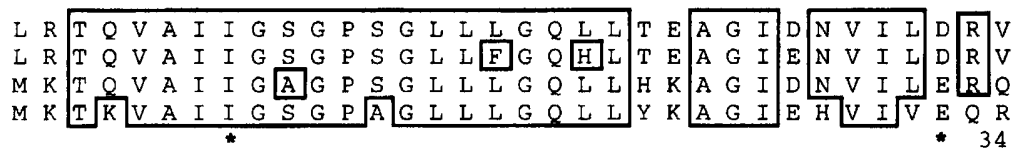

N K D Y I L G R V R A G V L EE G T V G L D D Q A R S G A R L H A E

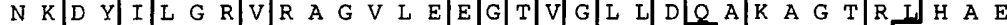

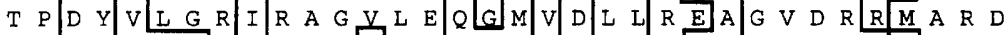

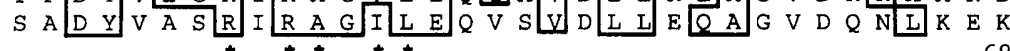

G L P H D GF S I AFD GR D H RID D H E TGGR R V T VYGQ G L P H D G L V H E G V E ILA_A A Q R R RI D L K R L S G G K T V T V Y G Q G L P H S G I E I I T N $L G Q$ K F R V D D L S A L T Q $G$ K Q Q V T V Y G Q

102

T E V T R D L M E R R E E S G S L S I Y D A V D V A P H D F D G P S T E V V T R T E V V T T R D L L M E A

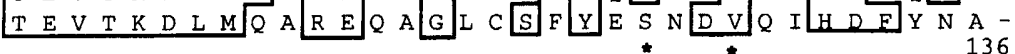

PF V T Y V K D G V A K R R I D C C D F F I A G G C D G F H

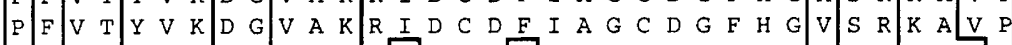

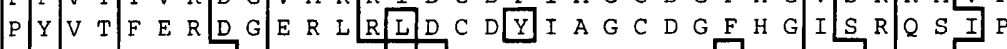
$\mathrm{P}$ K L V T F

E R A T R S F E K I Y P F G W L G I L A D V A P V S H E L I Y A N H

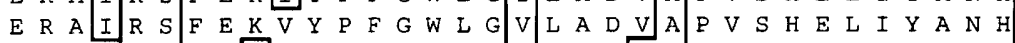
A E R L K V F E R V Y Y P F G W L G L L A D D T P P V S H E L I Y A N H

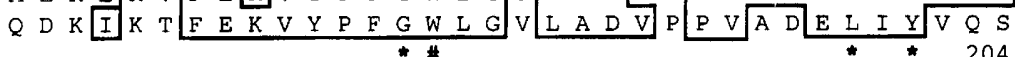

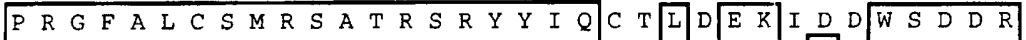
P R G G F A I C C S M R S A T R S

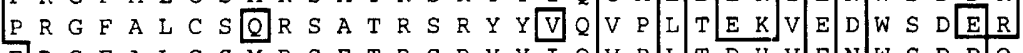

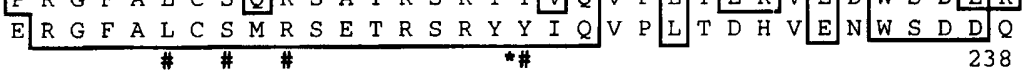

F W D D E L R R R R L P

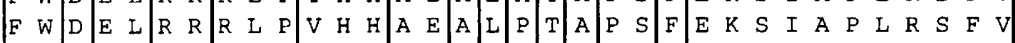

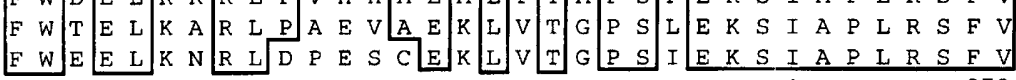

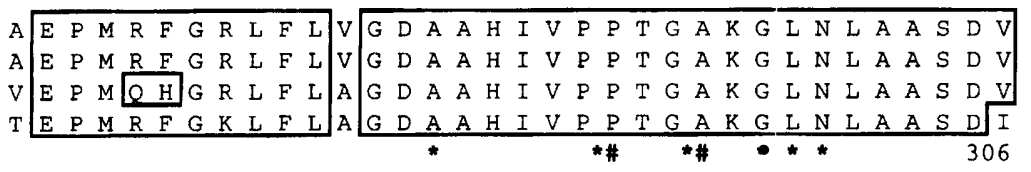

H Y L F S S G L I E E H Y R R E G S N S G G I D A Y S H R A

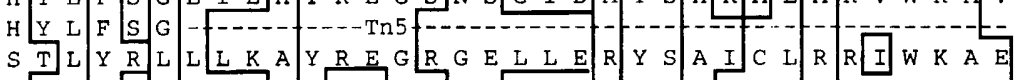

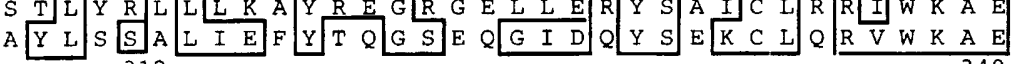
312

R F S W W T T M M H L F P D T G D F D Q K I Q E A E L D Y L T H S R E S W W M T S V L H R F P D T D A F S R R I Q O T E L E Y Y L G S

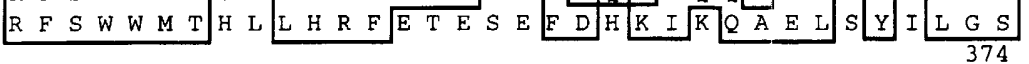

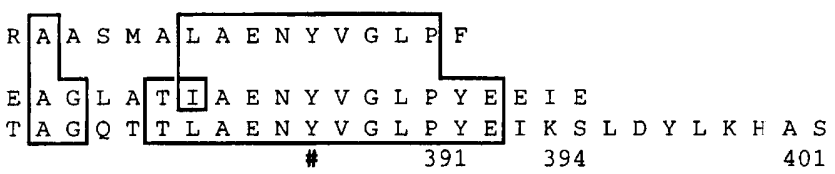

Fig. 3. Identity between amino acid sequences of pobA. Boxed regions indicate sequences where three or more of these strains are identical. The gap introduced into the amino acid sequence of $A$. calcoaceticus for the purposes of alignment is indicated by a dash. $1, R$. leguminosarum B155; 2, R. leguminosarum MNF300; 3, $P$. aeruginosa PAO1C (Entsch et al., 1988); 4, A. calcoaceticus ADP1 (DiMarco et al., 1993a); *, amino acids which are important for FAD binding in Pseudomonas; \#, amino acids which are important for substrate binding in Pseudomonas. examined to determine whether a regulatory pobR gene exists in Rbizobium. ORFs of $0.43 \mathrm{~kb}$ were found on the complementary strand of both the $2.0 \mathrm{~kb} \mathrm{R}$. leguminosarum
B155-complementing fragment and the sequences flanking Tn 5 in MNF300, extending through to the end of each of the fragments (Fig. 1a and b). 


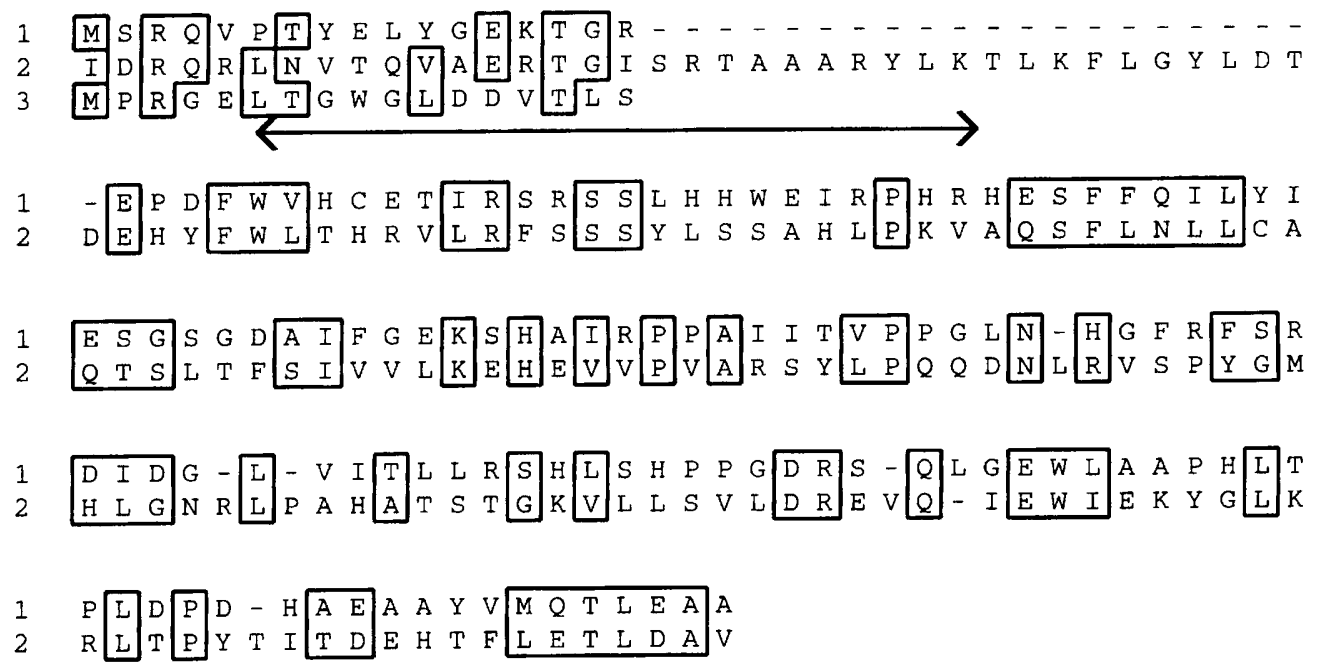

\begin{abstract}
Fig. 4. Similarity allowed by MacVector protein analysis software between amino-terminal amino acid sequences of pobR. A small number of amino acids have been included from the ORF found at the beginning of sequence data for the $P$. aeruginosa pobA (Entsch et al., 1988). The sequences underlined are those proposed for the helix-turn-helix motif in $A$. calcoaceticus (DiMarco et al., 1993b). 1, Amino acid sequence of pobR for $R$. leguminosarum; 2 , amino acid sequence of pobR for $A$. calcoaceticus; 3 , amino acid sequence of pobR for $P$. aeruginosa.
\end{abstract}

Regions of similarity of the B155 ORF to the $A$. calcoaceticus pobR are shown in Fig. 4. The consensus RBS sequence $5^{\prime}$ GGAG $3^{\prime}$ is separated from the translational start by 4 nucleotides (cf GGAGG separated by 4 nucleotides from the start codon of cat $\mathrm{R}$ in $A$. calcoaceticus; Rothmel et al., 1990). As in $A$. calcoaceticus, the pob $A$ and pobR genes appear to be transcribed divergently in $\mathrm{B} 155$ and MNF300, the separation being $130 \mathrm{bp}$ and $128 \mathrm{bp}$, respectively. The sequenced portion of the $p o b R$ gene (Fig. 4) contains information for a 142 amino acid segment of the amino-terminal portion of the PobR protein. In $A$. calcoaceticus, PobR contains 271 amino acids; if the protein is of a similar size in $R$. leguminosarum, this would suggest that about half the pobR gene has been sequenced. The 142 amino acid amino-terminal segment of PobR in $R$. leguminosarum has a very high ratio $(5 \cdot 5: 1)$ of arginine to lysine, analogous to $A$. calcoaceticus (DiMarco et al., 1988) and the rare arginine codon AGA is used twice in the corresponding regions of the genes in both organisms. These similarities to the $A$. calcoaceticus pob $\mathrm{R}$ are evidence that these sequences are part of pobR in $\mathrm{R}$. leguminosarum. Comparison of the sections of pobR obtained for B155 and MNF300 shows nucleotide homology of $95 \%$ and amino acid identity of $94 \%$.

\section{The role of pobA in the uptake of 4- hydroxybenzoate}

The demonstration that the gene mutated in MNF3030, MNF3036 and MNF9013 codes for 4-hydroxybenzoate hydroxylase suggests that this enzyme is involved in the uptake of 4-hydroxybenzoate. Previous work (Wong et al., 1991) had suggested, on the basis of inhibitor and substrate analogue studies, that 4-hydroxybenzoate uptake was active. We have now re-examined the mechanism of uptake of 4-hydroxybenzoate using the complemented strains.

\section{Assays of 4-hydroxybenzoate hydroxylase in wild- type and mutants}

In the earlier work (Wong et al., 1991), extracts from MNF9013 showed 4-hydroxybenzoate hydroxylase activity essentially the same as for the wild-type. Assays of hydroxylase activity (Table 3 ) in two of the complemented mutants (MNF3030C3 and MNF9013C3) carrying the $2.0 \mathrm{~kb}$ complementing fragment showed that they had enzyme activities which were comparable to that for the fully-induced wild-type MNF300 (37 $\mathrm{nmol} \mathrm{\textrm {min } ^ { - 1 }}$ ( $\mathrm{mg}$ protein $)^{-1}$. Enzyme assays were not carried out on complemented mutants carrying the larger plasmids (MNF3030C1, MNF3030C2, MNF9013C1 and MNF9013C2). None of the mutants showed significant hydroxylase activity (Table 3 ). Hydroxylase activity in MNF9010, a protocatechuate 3,4-dioxygenase (pcaHG) mutant (Wong et al., 1991) grown on 4-hydroxybenzoate $(2 \mathrm{mM})$ and glucose $(10 \mathrm{mM})$ was also measured to assess the degree of repression exerted by glucose when mutants such as MNF3030 and MNF9013 were grown in media containing glucose and 4-hydroxybenzoate. The hydroxylase activity in MNF9010 was $17 \%$ of that found for the fully-induced wild-type, a rate comparable to that expected 
Table 3. Rates of hydroxylase activity in $R$. leguminosarum pobA mutant MNF3030 and complemented pobA mutant MNF3030C3, and in $R$. trifolii pobA mutant MNF9013, complemented pobA mutant MNF9013C3 and pcaHG mutant MNF9010

The number of replicates is shown in parentheses. Replicates differed by no more than $20 \%$.

\begin{tabular}{|c|c|c|}
\hline Strain & $\begin{array}{c}\text { Carbon source(s) for } \\
\text { growth }\end{array}$ & $\begin{array}{c}\text { Enzyme activity } \\
{\left[\text { [nmol min }^{-1}\right.} \\
\left.(\mathrm{mg} \text { protein })^{-1}\right]\end{array}$ \\
\hline MNF300 & 4-Hydroxybenzoate & $37 \cdot 0(2)$ \\
\hline MNF3030 & $\begin{array}{l}\text { Glucose }+ \\
\text { 4-hydroxybenzoate }\end{array}$ & $0.03(2)$ \\
\hline MNF3030C3 & 4-Hydroxybenzoate & $49 \cdot 1(2)$ \\
\hline MNF9013 & $\begin{array}{l}\text { Glucose }+ \\
\text { 4-hydroxybenzoate }\end{array}$ & $0.67(2)$ \\
\hline MNF9013C3 & 4-Hydroxybenzoate & $30 \cdot 6(2)$ \\
\hline MNF9010 & $\begin{array}{l}\text { Glucose }+ \\
\text { 4-hydroxybenzoate }\end{array}$ & $6.6(2)$ \\
\hline
\end{tabular}

when the pathway is repressed by glucose (Dilworth et al., 1983; Wong et al., 1991).

\section{Effects of other compounds on hydroxylase activity}

When cells of the prototroph MNF300 grown on 4hydroxybenzoate were incubated with a 50 -fold molar excess of protocatechuate $(5 \mathrm{mM})$, accumulation of 4hydroxy $\left[{ }^{14} \mathrm{C}\right]$ benzoate was totally inhibited (Wong et al., 1991); similar experiments with 4-hydroxybenzaldehyde $(2 \mathrm{mM})$ showed a $100 \%$ inhibition of 4hydroxy $\left[{ }^{14} \mathrm{C}\right]$ benzoate accumulation whereas 2,5dihydroxybenzoate $(2 \mathrm{mM})$ caused only $29 \%$ inhibition. We had interpreted these data as implying competition for a transport system; an alternative explanation is that these compounds interfere with 4-hydroxybenzoate hydroxylase activity intracellularly.

In hydroxylase assays containing $0.3 \mathrm{mM} \quad 4-$ hydroxybenzoate, $0.1 \mathrm{mM}$ protocatechuate inhibited hydroxylase activity by $93 \% ; 0.6 \mathrm{mM}$ 4-hydroxybenzoate was able to overcome this inhibition, but not when protocatechuate was present at $1 \mathrm{mM}$. 4Hydroxybenzaldehyde (1 $\mathrm{mM})$ inhibited enzyme activity by $76 \%$, but 2,5 -dihydroxybenzoic acid at $2 \mathrm{mM}$ inhibited hydroxylase activity by only $17 \%$ and by $23 \%$ at $4 \mathrm{mM}$. These results are comparable with the degree of apparent inhibition of labelled 4-hydroxybenzoate accumulation by these hydroxyaromatic compounds.

Accumulation of ${ }^{14} \mathrm{C}$ from 4-hydroxy $\left[{ }^{14} \mathrm{C}\right]$ benzoate and $\left[{ }^{14} \mathrm{C}\right]$ protocatechuate in MNF300 was inhibited over $98 \%$ by $0.05 \mathrm{mM}$ CCCP (Wong et al., 1991), apparently indicating inhibition of an energized uptake system. However, when the enzyme reaction was allowed to proceed for $1 \mathrm{~min}$ [at $37 \mathrm{nmol} \mathrm{min}{ }^{-1}\left(\mathrm{mg}\right.$ protein) ${ }^{-1}$ ] prior to the addition of $0.025 \mathrm{mM}$ CCCP, enzyme activity fell to $17 \cdot 4 \mathrm{nmol} \mathrm{min}^{-1}$ (mg protein) $)^{-1}$. Addition of a further $0.025 \mathrm{mM}$ CCCP after $2 \mathrm{~min}$ lowered activity to $9 \cdot 1 \mathrm{nmol} \mathrm{m^{-1 }}$ (mg protein) ${ }^{-1}$; a further $0.1 \mathrm{mM}$ added after 5 min resulted in a final rate of $1.5 \mathrm{nmol} \mathrm{min}{ }^{-1}(\mathrm{mg}$ protein $)^{-1}$ (96\% inhibition).

Thus, the apparent effects of both hydroxyaromatic compounds and of metabolic inhibitors such as CCCP (Wong et al., 1991) on $\left[{ }^{14} \mathrm{C}\right]$ hydroxybenzoate accumulation may be explained by these compounds inhibiting 4hydroxybenzoate hydroxylase activity and preventing continued entry of labelled substrate into the cells.

\section{Growth on 4-hydroxymandelate}

Wong et al. (1991) reported very slow growth of both $R$. trifolii WU95 and MNF9013 on 4-hydroxymandelate in liquid media. A lesion in pob $A$ should not allow growth on 4-hydroxymandelate as sole carbon source because 4-hydroxymandelate must be converted to 4hydroxybenzoate to be metabolized. Paper chromatography of the original 4-hydroxymandelate failed to reveal any significant contamination. When this material was recrystallized, neither the wild-type strains (MNF300, WU95) nor the mutants (MNF3030, MNF3036, MNF9013) grew on 4-hydroxymandelate. Apparent growth of WU95 and MNF9013 on 4-hydroxymandelate in earlier work may have been due to microbial contamination or contamination of the medium with a carbon substrate other than 4-hydroxymandelate.

\section{Mechanism of uptake of 4-hydroxybenzoate and protocatechuate by $R$. leguminosarum}

Independently isolated mutants of $R$. leguminosarum MNF300 (MNF3030 and MNF3036) and R. trifolii WU95 (MNF9013) unable to grow on 4-hydroxybenzoate regained this ability when they carried a $2.0 \mathrm{~kb}$ fragment of $\mathrm{R}$. leguminosarum B155 DNA carrying only the pobA gene. When pob $A$ carries a $\operatorname{Tn} 5$ or $\operatorname{Tn} 5-233$ insertion, cells of $R$. leguminosarum or $R$. trifolii do not accumulate radioactive 4-hydroxybenzoate (Table 2 ), implying that this gene is essential for the continued entry of 4hydroxybenzoate. If these organisms also possessed an active 4-hydroxybenzoate permease system, it would be logical to expect 4-hydroxybenzoate accumulation to occur in mutants lacking the hydroxylase; this was not observed.

Whatever mechanism is suggested for the entry of 4hydroxybenzoate into rhizobial cells must be consistent with the observed rate of degradation of this substrate. Previous work described the stoichiometric conversion of 4-hydroxybenzoate to protocatechuate by a pcaHG mutant (MNF9010) of R. trifolii WU95 which, unable to further metabolize protocatechuate, secreted it into the medium (Wong et al., 1991). The rate of this conversion, ca $28 \mathrm{nmol} \mathrm{min}{ }^{-1}$ (mg protein) ${ }^{-1}$, gives an estimate of the rate of entry of 4-hydroxybenzoate into the cell consistent with the observed rate of uptake of 4 
hydroxy $\left[{ }^{14}\right.$ C] $]$ benzoate by MNF300 and with the observed activity of 4-hydroxybenzoate hydroxylase (Table 3).

Previous work has also suggested that separate systems exist for the uptake of 4-hydroxybenzoate and protocatechuate in the two biovars of $R$. leguminosarum (Wong et al., 1991). MNF3030, MNF3036 and MNF9013, which were unable to accumulate 4hydroxy $\left[{ }^{14}\right.$ (C]benzoate, grew on protocatechuate as sole carbon source and appeared (in 30 min uptake assays) to accumulate $\left[{ }^{14} \mathrm{C}\right]$ protocatechuate. If uptake of 4hydroxybenzoate is diffusive, the question arises as to whether uptake of protocatechuate is active or also occurs by diffusion. Short term ( $5 \mathrm{~min}$ ) uptake experiments with the protocatechuate dioxygenase $(p c a H G)$ mutant of $R$. trifolii, MNF9010, did not show accumulation of ${ }^{14}$ C]protocatechuate. The apparent accumulation of ${ }^{14}$ C]prot ocatechuate by MNF9010 over $30 \mathrm{~min}$ (Wong et al., 1991; may therefore indicate non-specific binding of $\left.{ }^{14} \mathrm{C}\right]$ protocatechuate to the cell surface over this period of time rather than uptake by the cell.

In the model we are proposing, 4-hydroxybenzoate is 'pulled' across the membrane as a result of its intracellular conversion to protocatechuate. Uptake of 4hydroxyhenzoate would therefore be via a passive mechanism dependent upon its metabolism. The existence of a lipid-soluble carrier for 4-hydroxybenzoate in the membrane of the cell is a possibility yet to be explored.

In addition to inducing catabolic genes, phenolic compounds typical of plants also induce genes required to form active associations with host plants. Thus, the formation of nodule-initiating oligosaccharides by rhizobia is induced by flavonoids exuded from growing legume roots (Peters \& Verma, 1990). To be effective at sites of transcription, these phenolic compounds must cross the cell membrane. It has been proposed that the $R$. leguminosurum nodD gene inducer, naringenin, traverses the outer membrane through aqueous pores and accumulates in the cytoplasmic membrane (Recourt et al., 1989). The mechanism for the diffusion of 4hydroxybenzoate is different; it must also pass into the cytoplasm for its subsequent catabolism to protocatechuate.

\section{ACKNOWLEDGEMENTS}

This work was assisted by a grant from the Australian Research Council.

\section{REFERENCES}

Ausubel, F. M., Brent, R., Kingston, R. E., Moore, D. D., Seidman, J. G., Smith, J. A. \& Struhl, K. (1988). Current Protocols in Molecular Biology. Niu Y'ork: John Wiley \& Sons.

Bae, Y. M. \& Stauffer, G. V. (1991). Mutations that affect activity of the Rhizainum meliloti $\operatorname{trp} E(\mathrm{G})$ promoter in Rbizobium meliloti and Escherichici colli. J Bacteriol 173, 5831. 5836.

Boyer, H. W. \& Roulland-Dussoix, D. (1969). A complementation analysis of the restriction and modification of DNA in Eschericbia coli. J Moi Biol 41, 459-472.
Brewin, N. J., Wood, E. A., Johnston, A. W. B., Dibb, N. J. \& Hombrecher, G. (1982). Recombinant nodulation plasmids in Rbizobium leguminosarum. J Gen Microbiol 128, 1817-1827.

Brown, C. M. \& Dilworth, M. J. (1975). Ammonia assimilation by Rbizobium cultures and bacteroids. J Gen Microbiol 86, 3948.

Chen, Y. P., Glenn, A. R. \& Dilworth, M. J. (1984). Lptake and oxidation of aromatic substrates by Rbizobium leguminosarum MNF3841 and Rhizobium trifolii TA1. FE.MS Microbiol Lett 21, 201-205.

De Maagd, R. A., Mulders, E. H. M., Canter Cremers, H. C. J. \& Lugtenberg, B. J. J. (1992). Cloning, nucleotide sequencing, and expression in Eschericbia coli of a Rbizobium leguminosarum gene encoding a symbiotically repressed outer membrane protein. I Bacteriol 174, 214221.

De Vos, G. F., Walker, G. C. \& Signer, E. T. (1986). Genetic manipulations in Rbizobium meliloti utilizing two new transposon Tn 5 derivatives. Mol \& Gen Genet 204, 485491.

Dilworth, M. J., McKay, I., Franklin, M. \& Glenn, A. R. (1983). Catabolite effects on enzyme induction and substrate utilization in Rhizobium leguminosarum. J Gen Microbiol 129, 359366.

DiMarco, A. A., Averhoff, B., Kim, E. E. \& Ornston, L. N. (1993a). Evolutionary divergence of $p o b . A$, the structural gene encoding $p$ hydroxybenzoate hydroxylase in an Acinetobacter calcoaceticus strain well-suited for genetic analysis. Gene 125, 2533.

DiMarco, A. A., Averhoff, B. \& Ornston, L. N. (1993b). Identification of the transcriptional activator $p o b \mathrm{R}$ and characterization of its role in the expression of pob.-1, the structural gene for $p$-hydroxybenzoate hydroxylase in Acinetobacter calcoaceticus. J Bacteriol 175, 4499-4506.

Ditta, G., Stanfield, S., Corbin, D. \& Helinski, D. R. (1980). Broad host range $\mathrm{DN} A$ cloning system for (iram-negative bacteria: construction of a gene bank of Rbizobium meliloti. Proc Natl . Acad S S US A 77, 7347-7351.

Doten, R. C., Ngai, K.-L., Mitchell, D. J. \& Ornston, L. N. (1987). Cloning and genetic organization of the pia gene cluster from Acinetobacter calcoaceticus. J Bacteriol 169, 31683174.

Downie, J. A., Hombrecher, G., Ma, Q.-S., Knight, C. D. \& Wells, B. (1983). Cloned nodulation genes of Rbirobium leguminosarum determine host-range specificity. Mol \& Gen Genet 190, 359365.

Entsch, B., Ballou, D. P. \& Massey, V. (1976). Flavin-oxigen derivatives involved in hydroxylation by p-hydroxybenzoate hydroxylase. J Biol Chem 251, 25502563.

Entsch, B., Nan, Y., Weaich, K. \& Scott, K. F. (1988). Sequence and organization of pob. 4 , the gene coding for p-hydroxybenzoate hydroxylase, an inducible enzyme from Pseudomonas aeruginosa. Ciene 71, $279 \cdot 291$.

Gray, J. X., Djordjevic, M. \& Rolfe, B. G. (1990). Two genes that regulate exopolysaccharide production in Rhizobium sp. strain NGR234: DNA sequences and resultant phenotypes. I Bacteriol 172, 193203

Hanahan, D., Jessee, J. \& Bloom, F. R. (1991). Plasmid transformation in Escherichia coli and other bacteria. Methods En izmol 204, 63113.

Harley, C. B. \& Reynolds, R. P. (1987). Analysis of $E$. coli promoter sequences. Nucleic. Acids Res 15, 23432361

Hartnett, G. B., Averhoff, B. \& Ornston, L. N. (1990). Selection of Acinetobacter calcoaceticus mutants deficient in the $p$-hydroxybenzorate hydroxylase gene $(p o b . A)$, a member of a supraoperonic cluster. $J$ Bacteriol 172, 6160-6161.

Hughes, E. J., Shapiro, M. K., Houghton, J. E. \& Ornston, L. N. (1988). Cloning and expression of pca genes from Pseudomonas putida in Eschericbia coli. J Gen Microbiol 134, 28772887. 
Johnston, A. W. B. \& Beringer, J. E. (1975). Identification of the Rhizobium strains in pea root nodules using genetic markers. I Gen Microbiol 87, 343-350.

Neidle, E. L. \& Ornston, L. N. (1986). Cloning and expression of Acinetobacter calcoaceticus catechol 1,2-dioxygenase structural gene cat $A$ in Escherichia coli. J Bacteriol 168, 815-820.

Neidle, E. L., Hartnett, C., Ornston, L. N., Bairoch, A., Rekik, M. \& Harayama, S. (1991). Nucleotide sequences of the Acinetobacter calcoaceticus ben $A B C$ genes for benzoate 1,2-dioxygenase reveal evolutionary relationships among multicomponent oxygenases. $J$ Bacteriol 173, 5385-5395.

Peters, N. K. \& Verma, D. P. S. (1990) Phenolic compounds as regulators of gene expression in plant-microbe interactions. Mol Plant-Microbe Interact 3, 4-8.

Raibaud, O. \& Schwartz, M. (1984). Positive control of transcription initiation in bacteria. Annu Rev Gen 18, 173-206.

Recourt, K., Van Brussel, A. A. N., Driessen, A. J. M. \& Lugtenberg, B. J. J. (1989). Accumulation of a nod gene inducer, the flavonoid naringenin, in the cytoplasmic membrane of Rbizobium leguminosarum biovar viciae is caused by the $\mathrm{pH}$-dependent hydrophobicity of naringenin. J Bacteriol 171, 4370-4377.

Rothmel, R. K., Aldrich, T. L., Houghton, J. E., Coco, W. M., Ornston, L. N. \& Chakrabarty, A. M. (1990). Nucleotide sequencing and characterization of $P$ seudomonas putida cat $R$ : a positive regulator of the cat $B C$ operon is a member of the LysR family. J Bacteriol 172, 922-931.

Rottenberg, H. (1975). The measurement of trans-membrane electrochemical proton gradients. J Bioenerg 7, 61-74.

Sambrook, J., Fritsch, E. F. \& Maniatis, T. (1989). Molecular Cloning: A Laboratory Manual, 2nd edn. Cold Spring Harbor, NY: Cold Spring Harbor Laboratory.

Shanley, M. S., Neidle, E. L., Perales, R. E. \& Ornston, L. N. (1986).
Cloning and expression of Acinetobacter calcoaceticus cat BCDE genes in Pseudomonas putida and Escherichia coli. J Bacteriol 165, 557-563.

Smith, I. (1960). Phenolic acids. In Chromatographic and Electrophoretic Techniques, Vol. 1, pp. 291-307. Edited by I. Smith. London: William Heinemann.

Stanier, R. Y. \& Ornston, L. N. (1973). The $\beta$-ketoadipate pathway. Adv Microb Physiol 9, 59-151.

Staskawicz, B., Dahlbeck, D., Keen, N. \& Napoli, C. (1987). Molecular characterization of cloned avirulence genes from race 0 and race 1 of Pseudomonas syringae pv. glycinea. J Bacteriol 169, 5789-5794.

Thayer, J. R. \& Wheelis, M. L. (1982). Active transport of benzoate in Pseudomonas putida. J Gen Microbiol 128, 1749-1753.

Van Berkel, W., Westphal, A., Eschrich, K., Eppink, M. \& De Kok, A. (1992). Substitution of Arg214 at the substrate-binding site of $p$ hydroxybenzoate hydroxylase from Pseudomonas fluorescens. Eur $J$ Biochem 210, 411-419.

Wheelis, M. L. (1975). The genetics of dissimilatory pathways in Pseudomonas. Annu Rev Microbiol 29, 505-522.

Wong, C. M., Dilworth, M. J. \& Glenn, A. R. (1991). Evidence for two uptake systems in Rhizobium leguminosarum for hydroxyaromatic compounds metabolized by the 3-oxoadipate pathway. Arch Microbiol 156, 385-391.

Yanisch-Perron, C., Vieira, J. \& Messing, J. (1985). Improved M13 cloning vectors and host strains: nucleotide sequences of the M13mp18 and PUC19 vectors. Gene 33, 103-119.

Yeh, W. K. \& Ornston, L. N. (1981). Evolutionatily homologous $\alpha_{2-2}$ oligomeric structures in $\beta$-ketoadipate succinyl CoA transferases from Acinetobacter calcoaceticus and $P$ seudomonas putida. $J$ Biol Chem 256, 1565-1569.

Received 31 December 1993; revised 6 June 1994; accepted 20 June 1994. 